\title{
Las Meditaciones suramericanas del Conde de Keyserling:

\author{
Su impronta en la filosofía de lo mexicano
}

\section{Keyserling's South American Meditations:}

\section{Their Influence on the Philosophy of lo Mexicano}

\author{
José Manuel Cuéllar Moreno*
}

RESUMEN: el objetivo es revisar las principales tesis del Conde de Keyserling en las Meditaciones suramericanas (1933) y demostrar su influencia en dos pensadores mexicanos: Samuel Ramos y Emilio Uranga. Tiene la doble originalidad de reivindicar a Keyserling como pieza clave para comprender el proceso de "germanización" de la filosofía mexicana durante los años veinte y treinta del siglo pasado, y de rastrear por primera vez la influencia de nociones keyserlinguianas como "hombre telúrico", "mundo abisal" y "gana" en los análisis sobre la finura y la desgana del mexicano. Se concluye que esta influencia no fue accesoria, sino decisiva, y que no se limitó a México. Por décadas, Keyserling alimentó el imaginario de filósofos y novelistas de toda Latinoamérica. El artículo adopta el presupuesto metodológico del historicismo: "una idea no viene a ser sino la forma de reacción de un determinado hombre frente a sus circunstancias".

Palabras Clave: Keyserling; Meditaciones suramericanas; Filosofía de lo mexicano; Samuel Ramos; Emilio Uranga.

ABSTRACT: The purpose of this article is to review Keyserling's main philosophical ideas and categories in his South American Meditations (published in German in 1932), and show the major influence they had on Mexican thinkers such as Samuel Ramos and Emilio Uranga. This articles vindicates the important role of Keyserling in the "Germanization" of Mexican Philosophy in the first half of the past century, and traces for the first time the presence of some Keyserling's notions ("hombre telúrico", "mundo abisal", "gana") in the characterization of the Mexican as delicate and unwilling. This influence was decisive and spread throughout Latin America. Historicism provides the methodological assumption that an idea (even a philosophical one) is nothing but a way a concrete human being deals with her circumstances.

Key wordS: Keyserling; South American Meditations; Mexican Philosophy; Samuel Ramos; Emilio Uranga.

Recibido: 28 de enero de 2020

Aceptado: 20 de agosto de 2020

Universidad Nacional Autónoma de México (jmcuellarm@hotmail.com). 
LA "GERMANIZACIÓN" DE LA "FILOSOFÍA

DE LO MEXICANO"

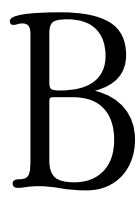

ajo la expresión "filosofía de lo mexicano" solemos reunir a un conjunto de autores y obras que van desde Antonio Caso y sus Discursos a la nación mexicana (1922) hasta El laberinto de la soledad (1950), de Octavio Paz, y el Análisis del ser del mexicano (1952) de Emilio Uranga, pasando por José Vasconcelos (La raza cósmica, 1925) y Samuel Ramos (El perfil del hombre y la cultura en México, 1934). El común denominador es la búsqueda de una filosofía auténtica y rigurosa: una filosofía que pudiese pensar y solventar las circunstancias específicas de México, con categorías vernáculas, no importadas, sin renunciar con esto a su vocación universal y a su capacidad de tender puentes con filosofías de otros países; más aún, su capacidad de servir de faro espiritual y moral ante el desastre europeo.

México se presentaba ante estos autores como la realidad inmediata, "como el dato más inmediato de su conciencia, como la única realidad en torno a la cual deberá girar toda la filosofía" (Zea 1947: 7). Había que dejar atrás, de una vez por todas, el vicio de la subsunción: el vicio de la adopción subalterna y la reproducción indefinida de los lenguajes científicos, filosóficos, académicos y artísticos globalmente sancionados. La búsqueda de una filosofía nacional era solo una instancia de un proceso de mayor envergadura y trascendencia: la batalla por la independencia cultural de México.

A esta "filosofía de lo mexicano" le fue concomitante un esfuerzo de profesionalización. El filósofo argentino Francisco Romero (1891-1962) acuñó el término "normalidad filosófica" para expresar la necesidad de los países latinoamericanos de profesionalizar la enseñanza de la filosofía, dejando atrás el autodidactismo y fomentando las publicaciones, debates y traducciones especializadas. En 1928 inauguró la cátedra de Gnoseología y Metafísica en la Universidad de Buenos Aires con una lección dedicada a Husserl. Samuel Ramos, en su Historia de la filosofía en México de 1943, entenderá la expresión de Francisco Romero, "normalidad filosófica", de una manera distinta, más cercana a la popularización y difusión que a la profesionalización: 
Ya no es la labor filosófica, como sucedía hace unos veinte años, una ocupación rara y excéntrica entre otras formas de cultura, sino una función normal. Hemos entrado, pues, dentro de la "normalidad filosófica", para usar una feliz expresión de Francisco Romero. Esto quiere decir que la filosofía tiene ya entre nosotros carta de naturalización, y su cultivo no depende solamente de una exigencia escolar; fuera de los recintos académicos, en todos los medios cultos se ha despertado un general interés por la filosofía. Los libros sobre esta materia cuentan ya con un crecido número de lectores. Multitud de artículos sobre temas filosóficos aparecen en revistas especializadas o no. La producción filosófica aumenta cada día. En la actualidad las personas que se dedican a los menesteres filosóficos no viven aisladas, sino que cuentan con un ambiente de atención e interés por sus trabajos (Ramos 1943: 160).

Una filosofía nacional y profesional era aquella que contaba con una organización y un soporte institucional sólidos, y aquella que, lejos de palidecer en su torre de marfil, se exponía a las inclemencias de la intemperie con tal de sacudir -y auxiliar- al hombre de a pie.

Ahora bien, esta profesionalización de la filosofía (en su acepción doble) coincidió, o se hizo coincidir, son su germanización. Hoy en día está muy difundida y asentada la creencia de que el Ateneo de la Juventud, en su justa intelectual en contra del positivismo (la supuesta ideología oficial del régimen de Porfirio Díaz), se inspiró muy principalmente en el espiritualismo y en la filosofía de la ciencia de cuño francés. "En la batalla filosófica contra el positivismo -recordaba Vasconcelos- el abanderado fue siempre Caso y nuestro apoyo Boutroux. El libro de éste, sobre la contingencia de las leyes naturales, hábilmente comentado, aprovechado por Caso, destruyó en un ciclo de conferencias toda la labor positivista de los anteriores treinta años" (1936: 266). Sería injusto no reconocer el influjo de Schopenhauer y Nietzsche en los empeños del joven Caso. De ellos heredó, además de una idea del arte como arte salvífico (el arte como un camino capaz de conducir al hombre a un plano superior de la existencia), una vigorosa actitud crítica. Sea como fuere, el excesivo "afrancesamiento" del Maestro Caso y su pomposa elocuencia levantaron suspicacias a finales de los veinte. Samuel Ramos, entonces una joven promesa de la filosofía, aún sin el prestigio de una copiosa obra, lideró la revuelta en contra del 
magisterio casiano. Para 1927, Boutroux, otrora vigente y mordaz, parecía anacrónico, con poco o nada que decir a unos jóvenes preocupados, ya no por el positivismo esclerótico de Díaz, sino por el porvenir de una Revolución mexicana urgida de lineamientos, programas e instituciones. Ramos, como se sabe, echó mano de las teorías de Alfred Adler (1870-1937), médico austriaco y discípulo cismático de Freud, para bosquejar un "perfil del hombre y la cultura en México". No todos los mexicanos recibieron de buena gana su diagnóstico de un "sentimiento de inferioridad".

Una de las principales enseñanzas y bondades del Maestro Caso era la de no preconizar ningún credo. Fustigado por las duras críticas de sus pupilos, guardó un silencio autoral que aprovechó para ponerse al día. Del aggiornamento de Caso surgieron los libros El acto ideatorio y La filosofía de Husserl, ambos de 1934. Este último incluía como apéndice la traducción del francés de algunos fragmentos de las Meditaciones cartesianas (1931).

La germanización de la filosofía estaba en marcha. Ramos se consagró al estudio de Max Scheler (De lo eterno en el hombre, 1921, y Sociología del saber, 1926). De estas lecturas extrajo la convicción de que en México debía hacerse una "sociología del conocimiento filosófico". A este propósito respondió en buena medida su ya mentada Historia de la filosofía en México. Otro filósofo que fue ampliamente leído y asimilado fue Nikolai Hartmann. Su impronta es perceptible en el libro de José Romano Muñoz, El secreto del bien y del mal (1938), en donde explica a los jóvenes "los problemas centrales de la ética y ofrece una respuesta a dichas preguntas desde la ética material de los valores de Max Scheler y Nicolai Hartmann" (Hurtado 2019: 15). La Escuela Nacional Preparatoria lo adoptó como libro de texto para la asignatura de Ética. A partir de entonces, y durante varias décadas, miles de jóvenes mexicanos aprendieron a recelar del empirismo y del determinismo éticos a favor del apriorismo axiológico de Scheler y Hartmann, "los autores alemanes más influyentes de la filosofía mexicana hasta mediados del siglo anterior, por encima de Windelband, Rickert, Natorp, Cohen, Dilthey, Husserl e incluso Heidegger" (15).

Heidegger distaba mucho de ser un desconocido. Como una de tantas pruebas puede esgrimirse Nostalgia de la muerte (1938) de Xavier Villaurrutia, donde las trazas del filósofo alemán son abundantes. 
"Sintiéndose desterrado, Villaurrutia entendía la muerte como patria del hombre" (Díaz Ruanova 1982: 33). ${ }^{1}$ En 1939, Adolfo Menéndez Samará publicó en Letras de México sus Dos ensayos sobre Heidegger, y un año después, en 1940, Agustín Yáñez publicó en Tiempo un artículo titulado "La nada en Martín Heidegger".

Por esos años (1938-1941) hicieron su arribo a México los exiliados españoles. Entre estos se contaba José Gaos (1900-1969), exrector de la Universidad de Madrid y discípulo directo de José Ortega y Gasset, considerado el mejor y más maduro filósofo en lengua española. Poco después atracó en costas mexicanas Joaquín Xirau Palau (1895-1946), exrector de la Universidad de Barcelona, un hombre de una solvencia intelectual intimidante. Y finalmente llegó el inquieto Juan David García Bacca (1901-1992), que hasta hacía poco había sido monje claretiano y que traducía a Platón, a Marx y a Heidegger; lo mismo enseñaba griego antiguo que divulgaba la axiomática de Reichenbach o la teoría cuántica de Heisenberg. Los tres exiliados (o "transterrados") españoles dieron un enérgico impulso a los estudios filosóficos. La filosofía alemana se afianzó como la filosofía vigente, en detrimento de la filosofía en lengua francesa (la lengua predilecta del Maestro Antonio Caso). "José Gaos, cuando llegó a México, ya venía contagiado por la manía de estimar altísimamente a Heidegger, y al Heidegger de Ser y tiempo, casi exclusivamente. El resto de los escritos de Heidegger no le suscitó jamás interés tan obsesivo" (Uranga 1983: 47). García Bacca se adentró en las tenebrosidades de Kant y el problema de la metafísica (Kant und das Problem der Metaphysik, 1929). También tradujo Hoelderling y la esencia de la poesía [sic], 1944. La errata en el título y en el cuerpo del texto -esa "g" sobrante- obligó a su pronta retirada del mercado.

Xirau tradujo del alemán la primera parte de Paideia: los ideales de la cultura griega (1942), ganándose la aprobación y los elogios del propio Werner Jaeger. Sus comentarios a la escuela fenomenológica los volcó

1 Manuel Durán, en su Antología de la revista Contemporáneos (1973), refiere lo siguiente: "[Villaurrutia] había leído al alemán Heidegger en una época en que nadie, o casi nadie, lo conocía en México". 
en las páginas, decisivas para los futuros hiperiones, de La filosofía de Husserl: una introducción a la fenomenología (1941). Sería cuestión de tiempo para que los crípticos filosofemas de Heidegger y las morosas traducciones del doctor Gaos provocaran el hartazgo y la irritación de toda una nueva hornada de filósofos.

En 1947 Leopoldo Zea auspició un grupo de estudios semi-oficial, conformado por Emilio Uranga (1921-1988), Luis Villoro (1922-2014), Jorge Portilla (1918-1963), Ricardo Guerra (1927-2007), Fausto Vega (19222015), Salvador Reyes Neváres (1922-1993) y Joaquín Sánchez Macgrégor (1925-2008). Las reuniones se celebraban en el Buen Tono de Bucareli y se prolongaban en el Café La Habana, el Café Bodón o La Rambla. Desgranaban las Críticas de Kant con el encarnizamiento textualista aprendido en las clases de los "transterrados". No es de extrañar que estos jóvenes hayan sido los primeros en deglutir con fruición las novedades editoriales que llegaban de Francia. La atmósfera optimista del régimen de Miguel Alemán, nuestro primer presidente civil y de extracción universitaria, terminó de convencer a los hiperiones de que en los yermos parajes de Heidegger no encontrarían las claves para una filosofía nacional. Los hiperiones dirigieron sus miradas y sus entusiasmos al existencialismo francés (el de Jean-Paul Sartre y Maurice Merleu-Ponty). Parecía que se completaba un ciclo. El pensamiento mexicano volvía a encontrar en Francia secretas afinidades y correspondencias.

Autoconocimiento (autognosis) del mexicano, independencia cultural, profesionalización y germanización eran las cuatro facetas de una misma empresa filosófica, la más notable y perdurable de la primera mitad del siglo xx. A la versión estándar de esta "germanización", que es la que hemos expuesto aquí grosso modo, nos gustaría añadir algunas notas y exactitudes. El recorrido de la "filosofía de lo mexicano" (de Caso a los hiperiones) no estaría completo sin una escala en el Conde de Keyserling, un pensador descomunal y de primer orden, considerado en su momento el máximo emblema de la filosofía y relegado en la actualidad a los pies de página. Sus tesis sobre el ser y el carácter del suramericano fueron retomadas y adaptadas en grandes porciones por los filósofos de lo mexicano. El Conde de Keyserling, valiéndose de su autoridad, extendió a los 
mexicanos, por decir así, una patente para hacer filosofía. No fue el único. Otros alemanes de indiscutible trayectoria, como Oswald Spengler, cedieron la batuta de la filosofía a los latinoamericanos en general y, muy en específico, a los mexicanos.

Nos interesa en lo que sigue ahondar en las tesis de Keyserling, tal y como las expuso en las Meditaciones suramericanas (1933). Habrá ocasión de destacar el importante papel de Primer Motor desempeñado por Alfonso Reyes.

Subyace a esta investigación el presupuesto historicista de que las ideas están irremisiblemente adscritas a una situación o circunstancia, frente a la cual ejercitan una función. "Una idea no viene a ser sino la forma de reacción de un determinado hombre frente a sus circunstancias" (Zea 1968: 20). Despojadas de su designio y de su finalidad históricas, tanto las tesis de Keyserling como las de los filósofos de lo mexicano - proveer a la filosofía de un humanismo no-occidental, consumar la independencia cultural de México- nos parecerían vagas, abstractas y carentes de sustento.

KEYSERLING: EL HOMBRE MÁS REPRESENTATIVO

DE LA HUMANIDAD CONTEMPORÁNEA

José Ortega y Gasset, a través de su Revista de Occidente y de su influjo en la editorial Espasa-Calpe, se convirtió desde 1923 en un surtidero privilegiado de novedades germanas, entre ellas La decadencia de Occidente (Der Untergang des Abendlandes, 1918, 1923) de Oswald Spengler y las Meditaciones suramericanas (Südamerikanische Meditationen, 1932) del Conde de Keyserling.

Hermann Alexander Graf Keyserling (1880-1946), a decir de Alfonso Reyes, era

el hombre más representativo de la humanidad contemporánea. Eslavo: por la figura y los reflejos, por el marco de la cara, la implantación de los ojos y el fruncimiento peculiar de la boca. Gigante. Familiar. Llano hasta subir los pies en las sillas, y sacudir y acariciar con las enormes manos hercúleas a su interlocutor [...] Bebe champaña sin cesar, y sigue hablando [...] 
Una actividad de trato a lo Lenin, y una necesidad a lo Rasputín de acercarse [...] a todos y cada uno de los hombres. Testarudo y poseído, pero enamorado de la libertad [...] Desde la frontera de los Estados Unidos sintió llegar [...] el aroma de la primavera mejicana. Esto le basta para entender a Méjico, y predice ya la mejicanización futura de toda la América del Norte (Reyes 2003: 75 y 76).

María Esther Vázquez, en su biografía de Victoria Ocampo (1991), refiere esta anécdota:

El conde [de Keyserling] fue instalado en el Plaza Hotel, en una suite que pagaba Victoria. A su llegada di una recepción en su honor, a la que invité (según su pedido) a una mezcla de intelectuales y de gente de mundo (la flor y nata). Él no dejó de beber en la reunión, con tal perseverancia, que terminó casi borracho. Mitad ebrio y brillante con todo el fuego de su elocuencia y de su espíritu, encantó e hizo reír a mis invitados, mientras a mí me invadía una rabia fría que no podía contener. Rodeado de profesores, de escritores, de mujeres hermosas, una mano apoyada sobre el hombro o sobre la cabeza (me parece que su mano también se apoyó en un momento en la cabeza) de Alfonso Reyes como un bastón (Alfonso parecía minúsculo a su lado), discurría, una copa de champagne en la otra mano. Cuando estos gestos se tornaban elocuentes, el champagne [...] desbordaba de la copa y los oyentes retrocedían para no ser salpicados, lo mismo que retroceden los caminantes sobre la playa, ante el avance de una ola (Vázquez 1991: 112 y 113).

La importancia del Conde de Keyserling para la "filosofía de lo mexicano" no ha sido lo suficientemente reconocida. Debajo de su personalidad y de su pensamiento animoso y profundamente vital, detrás de su brillantez y de su embriaguez, de sus "enormes manos hercúleas", se hallaba un hombre de salud quebradiza que pasaba largas temporadas (por lo menos tres meses al año) postrado en el lecho. Viajero infatigable, el conde de Keyserling encontró o reencontró en Suramérica, a finales de los veinte, "la matriz terrestre de toda vida", "la perspectiva desde la tierra" (1933: 31 y 41). "El paisaje suramericano constituye una reencarnación, todo lo atenuada que se quiera, del equilibrio entre lo animado y lo inanimado propio de aquellas edades primitivas en las que lo animado comenzó a ser lo determinante y conforme a leyes propias [...] En este continente, 
la distribución general de las fuerzas naturales es aún tal y como en todos los demás ha dejado de ser hace millares de años" (25 y 26). Suramérica se le presentó como una tierra "desordenada y vacía", evocación de tiempos primordiales, previos a la Creación definitiva, por eso llama a este el continente del "tercer día de la Creación". "Da éste, en un principio, la sensación de no hallarse sino a medias creado, de ser aún materia prima o un mero esbozo de la naturaleza" (40). Los suramericanos serían, si se quiere, hombres más "primitivos" o "salvajes" que el resto, "inacabados", a medio hacer, solo que estos términos no son descalificadores, muy por el contrario, indican un arraigo profundo en el mundo subterráneo o abisal, el mundo de la naturaleza indómita y discontinua, mundo de tinieblas, frente al mundo de la luz y del espíritu, el mundo de la conciencia reflexiva, de la coherencia y el sentido. "El suramericano es total y absolutamente hombre telúrico. Encarna el polo opuesto al hombre condicionado y traspasado por el espíritu" (41). Precisamente por esto, porque el suramericano se encuentra más próximo a la naturaleza telúrica que los pueblos intelectualizados, es que está en mejores condiciones de vivir la verdad primordial, "la cual es una conciencia de la debilidad, el hambre y el miedo primordiales" (46).

El mundo del tercer día de la Creación es uno poblado de horrores, de inseguridad y de violencia desenfrenada y gratuita, ante las cuales el hombre se sabe desnudo, vulnerable e impotente, sin voluntad, sin libre albedrío, arrastrado por el torrente ciego de la gana. Los suramericanos actúan, no por motivaciones o en obediencia a un proyecto o una imagen, sino porque les da la gana, un poder anónimo inarticulado que "obliga y ata como la fuerza de gravedad" (167). La impotencia primordial se manifiesta como pasividad, insensibilidad, culto a la apatía, de aquí la imagen del indio taciturno e impenetrable, rencoroso, fríamente cruel: el carácter contenido del suramericano es la contrapartida de su carácter explosivo. "Este indiferentismo que se extiende a través de todo el continente suramericano es uno de los fenómenos más impresionantes que conozco. No significa falta de interés, ni en general carencia ninguna: significa existencia ciega. Significa la primacía de la vida primordial en todo su impenetrable hermetismo" (152). 
Para el hombre telúrico, la muerte -el cotidiano poder matar o poder ser matado, devorar y ser devorado- se experimenta como ferocidad casi animal y como ingenua embriaguez de sangre, no como un acto útil ni como asesinato, es decir, no como un acto inmoral. Las categorías morales -"bien", "mal"- sobrevienen en un estadio posterior con la irrupción iluminadora del espíritu. "El instinto de violencia es un instinto normal, solo que perteneciente al mundo abisal y no al cenital" (77).

Lo esencial del mundo subterráneo es la ausencia de toda representación, la falta de una visión de conjunto. "Se trata de un abandono completamente irreflexivo, de segundo en segundo, a la pendiente y al ritmo de la vida primordial" (154). En ausencia de imaginación, los suramericanos han sido perfectos imitadores, cuando no perfectos improvisadores. "El azar reina soberanamente como en los tiempos de la Moira primitiva; incoherencia total e inconsecuencia absoluta. Y, sin embargo, la vida sigue, en fin de cuentas, un curso satisfactorio [...] Son muy pocos los suramericanos que toman completamente en serio sus actos, pues para ellos todo éxito es, en último análisis, hado o azar" (192 y 193).

La proximidad a la naturaleza implica sensibilidad finísima y susceptibilidad, no rudeza ni anquilosamiento de los sentidos, al revés de como se enseña, pues la atrofia de la sensibilidad y la excitabilidad hay que arrogársela en todo caso a la hipertrofia del intelecto. "Todo miedo demanda una salvaguardia. De aquí la primacía de la perífrasis sobre la expresión directa, de la etiqueta sobre la llaneza y de la cortesía sobre la franqueza, en las relaciones entre los hombres" (213). La dulzura en el habla y en las maneras del suramericano, su delicadeza ("espacio sin fricción"), su refinamiento, que suaviza todos los bordes ásperos de la realidad para evitar ser heridos ("hiperestesia del tacto"), responde justamente a la vivencia primordial del Infierno (otro nombre que el Conde de Keyserling da al mundo abisal, el mundo de la gana, por oposición al mundo de la autodeterminación). "La libertad no significa apenas nada para estos hombres. Su vida es esencialmente un padecer. Y, sin embargo, la orientación de su ánimo es progresiva. De esto sólo resulta ya un destino enteramente no-europeo" (134).

En Suramérica, prosigue el Conde de Keyserling, "reina casi ilimitadamente el peso original de la tierra [...] Por lo cual me parece indudable 
que habrá de producir algún día una civilización de gran profundidad en el sentido de la proximidad a la tierra" (160 y 161). A causa de esta proximidad, el suramericano acepta la muerte con "humilde naturalidad", con "una melancólica sonrisa indulgente, un supremo desdén". "Al fin y al cabo, los hombres están para verter su sangre y abonar con ella la tierra" (162).

\section{EL SÍMBOLO DE LA SERPIENTE ALADA}

El Conde de Keyserling, según sus propias palabras, se bajó del barco, en Argentina, "no para enseñar sino para aprender". Dejaba atrás una sociedad europea "superflua y esclerótica" y tenía delante, en Suramérica, una posibilidad de redención para toda la Humanidad. "Hoy en día, el prejuicio de que todo debe seguir las leyes de la inteligencia y la razón, ha oscurecido a los ojos de la mayoría de los hombres sus propias vivencias" (248). La absolutización de las leyes de la inteligencia y la razón es un "desalmamiento que conduce a la deshumanización y con ella a lo contrario de lo que en último análisis se propone el ideal progresivo. El concepto de humanidad tal y como en general es espontáneamente comprendido se refiere al sentimiento y no al entendimiento. No ha sido nunca al mentecato, sino al insensible al que se le ha calificado de "inhumano"" (252 y 253). "Cuando los fondos abisales son negados, sus energías, represadas, acaban por abrirse paso con multiplicada violencia devastadora, como ya lo han demostrado horrendamente la guerra mundial y la revolución mundial" (76), ya que "una racionalización exagerada es enemiga de la vida originaria" (278) y "la espiritualidad moderna no es ya alimentada por ninguna fuente profunda" (307). "iCuán profundo parece, comparado con la inmensa mayoría de los intelectuales europeos, el gaucho, que 'se persigna por las dudas'!" (307).

El Conde de Keyserling tenía claro que la nueva civilización debía ser una civilización profunda, firmemente anclada en la tierra, y que el nuevo hombre, decididamente un nuevo bombre suramericano, no debía renegar de su procedencia terrestre. El nuevo hombre que estaba incubándose en Suramérica abrazaría, domaría y se nutriría de su propia 
dimensión demoníaca. "El problema no puede consistir nunca, razonablemente, en transformar el mundo abisal como tal; de lo único que puede tratarse es de ponerlo al servicio del espíritu, del mismo modo que el asesino, hecho verdugo, se convierte en un servidor de la Justicia. Pero esto no puede producirse, a su vez, más que haciendo de lo espiritual un motivo de los instintos y tendencias del mundo subterráneo" (140). Por debajo de la muy intelectual (y a la postre brutal y fallida) investigación de la Verdad, sirviéndole de base y de origen, se hallan el hambre y el miedo primordiales. "Un mundo de espíritu totalmente orientado hacia las instituciones y del cual parece excluido todo sentimiento, como lo es el de la moderna civilización mecánica [...] es, a pesar de todo, más inhumano que cualquier mundo determinado por el alma, por malvado que en lo demás se muestre [...]. Los métodos comerciales de los americanos fuera de su propio país demuestran cuán inhumana es la actuación de un tal mundo, incluso en tiempos de paz" (280).

En la disputa continental entre el Norte y el Sur, este último era muy superior y mucho más profundo. Estados Unidos era tal vez más poderoso, pero en un sentido nimio y comercial y, sobre todo, en un sentido inhumano. "La inintelectualidad y la pasividad de Suramérica pueden conferirla en este viraje de la Historia una misión trascendental para la Humanidad" (235). "[Suramérica] puede producir, por vez primera después de tiempos dilatados, una cultura exclusivamente basada en la Belleza, que, sirviendo de polarizador al resto del mundo, entregado a una intelectualización sin tregua ni medida, señalaría a los hombres todos nuevas posibilidades y nuevos caminos" (238). ${ }^{2}$ El ideal sería vivir, como querría Buda, "acabadamente despierto", viendo la vida tal y como es, en todo su infernal horror.

Ahora bien, el presentimiento oscuro de una realidad extraterrestre o supratelúrica engendra en el hombre abisal -el hombre suramericano-

2 Compárese con este otro pasaje de Keyserling: "Quienquiera vive profundamente sus raíces telúricas, aunque nada sepa del espíritu vivo, está mejor preparado para acogerlo que todos los intelectualistas y todos los moralistas; y así, su ignorancia del espíritu vale más que toda la ciencia europea del espíritu, del mismo modo que la ignorancia de Sócrates valía más que la omnisciencia de los sofistas" (304). 
una tristeza primordial, una tristeza sin razones, sin fines, como una especie de "dolor flotante" que no es aún "sentimiento trágico de la vida", pues la tragedia surge de la contraposición de requerimientos, y en esta fase -la fase en que se encontraba Suramérica- el espíritu no levantaba todavía su reclamo... a excepción de México.

En Suramérica, hasta hoy, sólo en un lugar se ha llegado a la codeterminación por una conciencia verdaderamente metafísica: en Méjico. Por consiguiente, la tristeza mejicana es la única que tiene como componente el sentimiento trágico de la vida. Sin embargo, el símbolo de la religio con un más allá es distinto de todos los demás en la tierra. Es la serpiente alada. El animal que repta sobre el vientre y come tierra quiere echar a volar. Pero sólo es capaz de un corto vuelo (323).

El símbolo de la serpiente alada funde, como ningún otro símbolo en la tierra, el sentimiento de la ley telúrica (el Infierno) con la exigencia del espíritu (el camino ascendente al Cielo). Mientras Europa se desentendía de la vida originaria, ahíta de razonamientos abstractos, recluida en una realidad espiritual hipostasiada, México, sin romper sus lazos con la tierra, despertaba apenas a la vida iluminadora del espíritu, y con este despertar se abrían para el hombre, para la Humanidad, nuevas promesas de una espiritualización dotada de gravedad terrestre y de la valerosa facultad de sufrir. "Pervive en él [el mexicano] el sombrío heroísmo de los aztecas, aunque deformado en ocasiones hasta lo melodramático. Pero los mejicanos son, sin duda, un pueblo fuerte, y experimenta quizá una importante resurrección" (115 y 116). La resurrección de México implicaba la resurrección de todos los hombres.

\section{OSWALD SPENGLER: TEMA DE SALÓN}

La predicción de una primavera mexicana sonaba atractiva y en consonancia directa con el ánimo de construir a un nuevo hombre luego de la hecatombe revolucionaria. La predicción quedaba además sostenida por las teorías en pleno apogeo de Oswald Spengler. Para el filósofo alemán, cada civilización es un superorganismo con una esperanza de vida limitada 
y predecible. Las culturas, como los cuerpos individuales, atraviesan un ciclo vital compuesto por cuatro etapas: juventud, crecimiento, florecimiento y decadencia. La lectura de este libro impresionó hondo en el público mexicano. Lo leyeron iniciados y no iniciados embargados por una extraña sensación de "inminentismo": la decadencia irremediable de Europa bien podía significar que por fin había llegado su hora de esplendor a América. "Spengler se puso de moda. Se convirtió en tema de salón. En asunto de plática obligada. Pronto germinó la idea de la novedad. Ortega hizo de Alemania la tierra de las novedades incitantes, la inagotable fuente de revelaciones. Lo que había sido Francia por mucho tiempo vino a serlo ahora Alemania. Del nihilismo a la reconstrucción". ${ }^{3}$ Los ateneístas habían acometido una labor destructiva o de desmantelamiento de una filosofía (y por añadidura de una realidad social) ya caduca. Tocaba el turno -la hora- de la reconstrucción y, por ende, de la superación de los maestros. Convenía para este propósito buscar apoyo en aquellos alemanes que como Keyserling o Spengler alzaban su índice para señalar a América. ${ }^{4}$

Spengler y Keyserling no eran voces aisladas. Al lado de ellos, en las primeras filas del coro, era posible hallar al economista Adolfo Reichwein

Diario alemán de Emilio Uranga (1954-1955), AEU, c. 1, exp. 2, f. 72.

4ax Scheler (1874-1928) fue otro de los filósofos alemanes cuyo pensamiento arraigó en México durante los años treinta gracias a las traducciones de la Revista de Occidente (Esencia y formas de la simpatía, 1923, El resentimiento en la moral, 1927, El puesto del hombre en el cosmos, 1929, Sociología del saber, 1935, traducidos directamente del alemán por José Gaos). Scheler había sido una de las primeras voces en alertar sobre el crepúsculo de casi todo el mundo civilizado y la llegada del nazismo. Antonio Caso, abierto y efusivo simpatizante de Scheler, recogía la siguiente cita en un artículo de 1937: "Un verdadero terror se apodera de mí ante el creciente abandono de las libertades y la pérdida de la sensibilidad, crepúsculo gris e informe en que, no sólo éste o aquel país, sino casi todo el mundo civilizado, se halla en grave peligro de hundirse, de ahogarse lentamente, casi sin darse cuenta" (Max Scheler citado por Antonio Caso en "La palabra de admonición", El Universal. 5 de noviembre de 1937). El estudio mexicano de Scheler prosperó bajo el magisterio de José Gaos y Joaquín Xirau, extendiéndose hasta bien entrados los años cincuenta. Véase Emilio Uranga, "Reflexiones de Max Scheler sobre la esencia de la filosofía", texto inédito de 1959 depositado en el Fondo Luis Villoro del Instituto de Investigaciones Filosóficas de la UNAM. 
(1898-1944). El libro de Reichwein llevaba el contundente título de El despertar de Méjico, fue publicado en 1930 y traducido al español en 1931.

Presentar a Méjico como ejemplo: tal es el designio del presente libro [... ] La existencia de Europa está amenazada por el desmoronamiento de su orden social y el creciente poderío autónomo de los continentes que ella colonizó en otro tiempo [...] Se ha quebrantado la posición prepotente de Europa, su fuerza para dictar [...] Se van soltando las amarras seculares que nos enlazaban con los países ultramarinos [...] Por eso lo que actualmente ocurre al otro lado del mar no ha de considerarse como objeto superfluo de investigación erudita, sino como algo que debe interesar a todo aquel a quien importe la existencia de Europa [...] Méjico es el campo donde ambos movimientos [el de las dos Américas: el coloso del Norte y el Sur latino e indio] se compenetran hoy de la manera más clara; es un modelo en pequeño de lo que representará la futura Panamérica federal, la América que puede vivir y vivirá sin Europa (Reichwein 1931: 5-7).

México, "de quien no se sabía otra cosa sino que en él había sombreros típicos y cactáceas, indios y aventuras" (15), lanzaba ahora vivos destellos hacia Europa, y para mostrar la viveza de estos destellos, para mostrar que México era más que esos sombreros y esos cactus y esos indios de historieta, Reichwein incluía en su libro 15 mapas y 48 ilustraciones. Cosa curiosa: en la mayoría se aprecian cactus y sombreros.

\section{LA HORA DE AMÉRICA}

"La hora de América" se impuso como la frase en boga de este periodo. Se trataba sin embargo de una frase de dilucidación ambigua, ya que bien podía significar el florecimiento de América sobre las ruinas de Europa como el tesón americano por nivelarse al fin a la cultura europea. Alfonso Reyes, en su "Discurso por Virgilio", pronunciado en agosto de 1930, se decantaba por la segunda interpretación:

No debemos entender que se ha levantado un tabique en el océano, que de aquel lado se hunde Europa comida de su polilla histórica, y de acá nos levantamos nosotros, florecientes bajo una lluvia de virtudes que el cielo nos ha ofrendado por gracia $[. .$.$] No: hora de América, porque apenas va$ 
llegando América a igualar con su dimensión cultural el cuadro de la civilización en que Europa la metió de repente; porque apenas comenzamos a dominar el utensilio europeo. Y hora de América, además, porque este momento coincide con una crisis de la riqueza en que nuestro continente parece salir mejor librado [...] En el crisol de la historia se prepara para América una herencia incalculable. Pero será a condición de vivir alerta, de aprovechar y guardar todas las conquistas (Reyes 1960a: 171).

Alfonso Reyes se desempeñaba como diplomático en Río de Janeiro, no escribía con el vaho de la sangre bajo la nariz, por lo que sorprende el hecho de que no se le escaparan los fragores del tumulto social. Para Reyes la "x" de México era una incógnita a despejar, pero también un cruce de innumerables caminos, punto de encuentro y hasta de encontronazo entre Oriente y Occidente, la América del Norte y la América del Sur, el catolicismo hispano y el paganismo azteca. Los mexicanos no podíamos sentarnos sobre un lecho de virtudes a esperar el advenimiento de una primavera prometida. Reyes prefiguraba de este modo la tesis antiesencialista de que el mexicano en sentido estricto no es nada más que una "x" en busca de un referente, un sentido y un valor: "nuestra conducta de americanos está en acoger todas las conquistas, procurando con todas ellas una elaboración sintética" (174). El pensador regiomontano se mantenía atento a los fragores sin dejarse ensordecer y con la mirada puesta, como su compañero de generación, Antonio Caso, en el orden superior de la existencia, que es el orden de los ideales: "está en juego un alto interés humano, no una mezquina ambición. Lo que ha de salir [será] amplia y totalmente humano" (173). Hora de América, no de México únicamente, y quizás tampoco de los propios americanos, sino del hombre. "Adoptémoslo todo y tratemos de conciliarlo todo" (172). Hora de trabajo y de concordia.

La concordia, a semejanza de la unidad nacional de Antonio Caso, era un esfuerzo activo de síntesis -la hora de América había de alcanzarse, los mexicanos debíamos hacernos a nosotros mismos un receptáculo propicio y fértil para la herencia-. Reyes no proponía tanto la homogeneización o mestización de la cultura mexicana (aquello hubiera sido proponer equivocadamente como ideal una suerte de hora gris del mestizo), como 
la amistad provechosa. ${ }^{5}$ La concordia se planteaba como síntesis que en lugar de anular las diferencias o de subsumirlas, se valía de ellas para trazar las grandes orientaciones de la existencia humana, "a condición de vivir alerta, aprovechar y guardar todas las conquistas". No habría síntesis sin reflexión ni recogimiento:

Este descenso a los pozos ocultos de nuestra psicología colectiva; esta inmersión en los vasos comunicantes de la subconsciencia, donde cada hombre es injerto de antepasados y, sin abdicar nuestra dignidad de individuos, todos nos sabemos atados en igual tronco, del mismo modo que las hojas, sin dejar de ser la sola unidad vegetal, el órgano por esencia del árbol, se sienten atadas en su árbol (Reyes 1960a: 165).

Subrayemos los elementos centrales de la propuesta de Reyes: la hora de América era 1) un momento de toma de conciencia, 2) un quehacer, 3) un esfuerzo de concordia, no precisamente de unidad, 4) una obra mexicana "que haga al fin de ella un patrimonio universal [pues] ¿qué diría Platón del mexicano que anduviera inquiriendo una especie de bien moral sólo aplicable a México?" (179). La hora de América era finalmente 5) una hora de profesionalización, "enseriamiento" e institucionalización ("el dominio del utensilio europeo"). Para algunos pensadores este mandato equivaldrá también al de germanizar la filosofía.

"Concordia", "trabajo" y "responsabilidad" eran los tres conceptos que sustentaban al México de Reyes, pero más importante que estos conceptos será el programa de estudio y de vida que entregue a los jóvenes. Serán ellos los que en los años subsecuentes practicarán el descenso a los pozos ocultos de nuestra psicología colectiva.

5 Desde Visión de Anábuac (1915) Alfonso Reyes combatía la imagen bárbara del México pre-colombino. Le interesaba demostrar que la azteca era una civilización clásica como podía serlo la civilización china antigua, la egipcia o la griega, y esto con el fin de ensalzarla a fuente de aprendizaje de valores universales. "Si esa tradición [la nahua] nos fuere ajena, está como quiera en nuestras manos, sólo nosotros disponemos de ella. No renunciaremos -oh, Keats- a ningún objeto de belleza, engendrador de eternos goces" (Reyes 1956: 34). 


\section{CONClusiones}

Precedía al Conde de Keyserling una abundante literatura de viajes que se remontaba a las crónicas de la Conquista. No era la primera vez, ni por asomo, que un expedicionario europeo retrataba puntillosamente al suramericano. En México -nótese que para Keyserling México forma parte integral de Suramérica- contábamos con el antecedente decimonónico de Madame Calderón de la Barca, por mencionar tan solo un nombre. No era la primera vez que el suramericano comparecía ante el tribunal de la Razón Moderna, bajo la acusación de ser un bárbaro, un primitivo; de no participar de los altos valores de Occidente; de resistirse al progreso técnico y civilizatorio; de no ceñir su conducta a ningún plan racional; de vivir al día y a merced de una fuerza hierática y azarosa, innominada; de no ser, en suma, un hombre pleno, sino un hombre inacabado, a medio hacer. Las Meditaciones suramericanas de Keyserling, compendiando muchos de los elementos anteriores, arrojaban un saldo distinto. Esta era la novedad. El Conde, en vez de escandalizarse o de condenar como terribles vicios las prácticas incivilizadas y el carácter rejego de los suramericanos, los exaltaba, y en vez de excluir a estos "hombres inacabados" como agentes de la cultura y de la historia, los presentaba como el futuro y la esperanza de la humanidad. Europa había perdido su sentido terrestre, su contacto con la modesta condición humana, y el excesivo idealismo de sus intelectuales, más que una conquista, parecía "cobardía ante la realidad". "Si la raíz se seca, las hojas o las flores mueren sin remedio" (Keyserling 1933: 278).

Desde esta óptica, el inhumano, el hombre mutilado, el que debía comparecer por los atroces crímenes cometidos y dejarse enseñar guiar-por el otro, no era el suramericano, sino -en un dramático cambio de posiciones- el europeo. El histórico recelo de Suramérica ante los progresos de la técnica y ante la incursión de la modernidad, parecía ahora -luego de una guerra mundial- una envidiable ventaja.

La filosofía de Keyserling tenía un marcado tono cínico, entendido este cinismo, junto con Nietzsche, como inversión de los valores. "El cinismo - escribirá Uranga- es necesario para regodearse con alegría en nues- 
tros defectos". ${ }^{6}$ Lo que antes se juzgaba "atrasado" e "incivilizado", quedaba ahora convertido en un acto vanguardista de disidencia. 7 "El cínico manifiesta plétora vital y no apocamiento o tibieza. Es actitud de rebeldía señorial frente al complejo de inferioridad que es una rebelión sumisa, al fondo, o una sumisión rebelde. El cínico es desenfadado y audaz, desafía y se mete con un mundo de valores 'superiores' con el decidido y consciente propósito de ponerlo de cabeza" (Uranga 2013: 75).

Al lado de El carácter neurótico (1921), de Alfred Adler, es posible imaginar, en el escritorio de Samuel Ramos, un ejemplar de las Meditaciones suramericanas. Expresiones de Ramos como "la voluntad de lo inmutable del indígena", "la imitación irreflexiva" o "la pasión [fuerza bruta y sin sentido que desafía toda razón] es la nota que da el tono a la vida de México" exhalan un tufillo keyserlinguiano. Lo mismo podría decir de Salvador Reyes Nevárez y su análisis de la "finura". "Como en todo, somos individuos de oscilaciones, que, si bien mantienen regularmente su fina manera de ser y de portarse, también son dados a transitar al polo opuesto. En México es tan natural la cortesía extremada como la violencia, la crueldad también llevada a sus últimos límites" (Reyes Nevárez 1952: 15 y 16).

De acuerdo con Oswaldo Díaz Ruanova, "en las Meditaciones suramericanas, de Hermann Keyserling, halló Uranga la principal idea de desgana, que en alguna de sus conferencias ilustró con Bartleby, un curioso personaje de Melville que no quiere ser nadie ni quiere hacer nada" (1982: 187). En el famoso Ensayo de una ontología del mexicano (1949), de Uranga, la desgana es una de las actitudes que mejor patentizan la constitución originaria e insuficiente del mexicano. "En la desgana el ánimo se colora de cierta repulsión por las cosas, de una callada abominación

AEU, c. 1, exp. 2, f. 37.

El 13 de abril de 1944, el profesor Gaos dictó una ponencia con el sugerente título de "El pensamiento hispanoamericano": "Los países de lengua española parecen singularmente vocados por su antagonismo a la modernidad a cooperar creadoramente al advenimiento de la nueva comunión" (1991: 43). Gaos refrendó su postura en un discurso de 1946: "A la luz de un cambio histórico como el que se insinúa, su decadencia puede llegar a parecer disidencia, disidencia de las estimaciones de la modernidad" (1992: 477) 
por cuanto nos rodea" (Uranga 1949: 137). El mexicano adopta este sentimiento para no decidir, o mejor dicho, para decidir no decidiendo, de aquí que la desgana sea una suerte de "irresponsabilidad consentida" y una "indiferencia ante una súplica" (137-38). La disciplina y la seriedad se oponen a la desgana, que Uranga terminar de definir en otro lugar como "la falta de generosidad y la resistencia pasiva".

Prestemos atención al siguiente párrafo de Keyserling:

Al principio [los pueblos] obedecen mal al espíritu. Por eso la primera tendencia de toda humanidad llegada a la conciencia de su determinación espiritual ha sido establecer y dictar, con toda ingenuidad, preceptos contrarios a la pendiente de la naturaleza. El hombre 'debía' ser distinto de lo que es. Mas como no lo era, ni podía transformar la realidad a su antojo, se originó una situación, de la que surgió, no sólo el mandamiento de iSé quién eres! [sic], sino también la tendencia a construir y proyectar ante sí una imagen falsa de sí mismo que le fingiera una consoladora superación de su insuficiencia (1933: 363).

En este pasaje se ofrece otra explicación (¿o una explicación complementaria?) al bovarismo nacional (Antonio Caso) y al sentimiento de inferioridad del mexicano (Samuel Ramos), con su subsecuente compulsión imitativa, y aparece la categoría de "insuficiencia", con la que más tarde Uranga pretenderá superar los análisis de sus predecesores.

Son numerosos los casos en que se percibe a simple vista la impronta de Keyserling. Estoy convencido de que rastrear estas huellas es indispensable para arrojar nuevas luces sobre la "filosofía de lo mexicano", hoy injustamente desatendida.

México no fue el único país que prestó oídos a las profecías del Conde de Keyserling. Este "profeta profesional" (Reyes 1960b: 138) alimentó durante décadas la imaginación de filósofos y novelistas latinoamericanos. Se le percibe, de refilón, en Radiografía de la pampa (1933), de Ezequiel Martínez Estrada, y de manera más notoria en Historia de una pasión argentina (1937), de Eduardo Mallea, o en El pecado original de América (1954), de Héctor A. Murena. Christopher Domínguez Michael ha vislum- 
brado trazas de Keyserling en Residencia en la tierra (1935), de Pablo Neruda, y en Los muros de agua (1941), de José Revueltas (Domínguez Michael 2013). Se han subrayado, también, las "plausibles afinidades" entre el conde alemán y las novelas de Ernesto Sábato (Lojo 2010).

Es posible que las ideas-imágenes-profecías del Conde de Keyserling, convertidas en moneda corriente, hayan terminado por emanciparse y por hacer de su autor, o un decorado de trasfondo, o una curiosa antigualla.

\section{BiBLIOGRAFÍA}

CALDERÓn de la BARCA, Frances. Life in Mexico During a Residence of Two Years in That Country. Londres: Chapman and Hall, 1843.

Caso, Antonio. Discursos a la nación mexicana. México: Librería de Porrúa Hermanos, 1922.

CAso, Antonio. El acto ideatorio. México: Librería de Porrúa y Hermanos, 1934.

Caso, Antonio. La filosofía de Husserl. México: Imprenta Mundial, 1934.

Díaz Ruanova, Oswaldo. Los existencialistas mexicanos. México: Rafael Giménez Siles, 1982.

Domínguez Michael, Christopher. "Radiografía del laberinto". Letras Libres 173 (2013): 42-49.

Durán, MANuel. Antología de la revista Contemporáneos. México: FCE, 1973.

García BACCA, JUAN DAVID. Hoelderling y la esencia de la poesía. México: Séneca, 1944.

GAOS, José. "El pensamiento hispanoamericano". Obras completas V. MéxiCO: UNAM, 1991.

GaOS, José. "La decadencia". Obras completas IX. México: UnAM, 1992: 477-482.

HurTADO, Guillermo. "El secreto del bien y del mal". Artículo en línea disponible en https://www.razon.com.mx/opinion/el-secreto-del-bien-ydel-mal/ (consultado el 15 de octubre de 2019).

JAEGER, WERnER. Paideia: los ideales de la cultura griega, trad. de Joaquín Xirau. México: FCE, 1942. 
KeYSERLING, CONDE DE. Meditaciones suramericanas. Madrid: EspasaCalpe, 1933.

LOJO, MARÍA ROSA. "Ernesto Sábato y Hermann von Keyserling: iafinidades electivas? Sudamérica, el continente 'ciego"'. Inti: Revista de literatura bispánica 71 (2010): 9-27.

MALLEA, EDUARDO. Historia de una pasión argentina. Buenos Aires: Sur, 1937.

MarTínez EsTRaDA, EZEQUiEL. Radiografía de la pampa. Buenos Aires: Babel, 1933.

MenÉndez SAmará, ADOLFo. Dos ensayos sobre Heidegger. México: Letras de México, 1939.

Murena, HÉCtor A. El pecado original de América. Buenos Aires: Sur, 1954.

PAZ, OCTAVIO. El laberinto de la soledad. México: Cuadernos Americanos, 1950.

RAMOS, SAMUEL. El perfil del hombre y la cultura en México. México: Imprenta Mundial, 1934.

RAMOS, SAMUEL. Historia de la filosofía en México. México: UNAM, 1943.

Reichwein, Adolfo. El despertar de Méjico. Madrid: Cenit, 1931.

ReYES, AlfONSO. "Visión de Anáhuac". Obras completas II. México: FCE, 1956. 9-34.

REYES, ALFOnSO. "Discurso por Virgilio". Obras completas XI. México: FCE, 1960a. 157-177.

REYES, ALFOnSO. "Keyserling en Buenos Aires". Obras completas XII. MéxiCO: FCE, 1960b. 138-140.

REYES, ALFONSO. Libra 1929. Edición facsimilar preparada por Rose Corral. México: El Colegio de México, 2003.

REYES NEVÁREZ, SALVADOR. El amor y la amistad en el mexicano. México: Porrúa y Obregón, 1952.

ROMANO MuÑOZ, JosÉ. El secreto del bien y del mal: Ética valorativa. México: Antigua Librería Robredo, 1938.

SCHELER, MAX. Sociología del saber. Madrid: Revista de Occidente, 1935.

SCHELER, MAX. De lo eterno en el hombre. Madrid: Revista de Occidente, 1940. 
SPengler, Oswald. La decadencia de Occidente. Bosquejo de una morfología de la bistoria universal I-IV. Madrid: Espasa-Calpe, 1923-1925. Uranga, Emilio. "Ensayo de una ontología del mexicano". Cuadernos Americanos 54.2 (1949): 135-148.

Uranga, EMilio. "Heidegger en México". Nexos 72 (1983).

URAnga, Emilio. Análisis del ser del mexicano. Pról. y notas de Guillermo Hurtado. México: Bonilla Artigas, 2013 (Las Semanas del Jardín, 4).

VASCONCElos, José. La raza cósmica. París: Agencia Mundial de Librería, 1925.

VASCONCELOS, José. Ulises criollo: la vida del autor escrita por él mismo. México: Ediciones Botas, 1936.

VÁZQUEZ, MARÍA ESTHER. Victoria Ocampo. Buenos Aires: Planeta, 1991.

Villaurrutia, Xavier. Nostalgia de la muerte. Buenos Aires: Sur, 1938.

XIRAU, JOAQuín, La filosofía de Husserl: una introducción a la fenomenología. Buenos Aires: Losada, 1941.

YÁÑ̃z, Agustín. "La nada en Martín Heidegger". Tiempo 5 (1940).

ZEA, LEOPOLDO. "La filosofía en México. Antonio Caso". El Nacional. México, 27 de abril, 1947.

ZEA, LEOPOLDO. El positivismo en México: nacimiento, apogeo y decadencia. México: FCE, 1968.

ARCHIVOS CONSULTADOS

Archivo Emilio Uranga, Instituto de Investigaciones Filosóficas de la UnAM. 